\title{
Influence of a Breastfeeding Coaching Program on the Breastfeeding Rates and Neonatal Morbidity in Late Preterm Infants
}

\author{
Gun Ja Jang \\ Associate Professor, Department of Nursing, Daegu University, Daegu, Korea
}

Purpose: This study aimed to determine the influence of a breastfeeding coaching program (BCP) for mothers of late preterm infants (LPIs) on the breastfeeding rate and neonatal morbidity within 1 month after discharge. Methods: This was a non-randomized quasi-experimental study with a time series design. The participants were 40 LPIs and their mothers who were hospitalized in a neonatal intensive care unit at a university hospital. Nineteen LPIs were assigned to the control group, and 21 to the experimental group. The mothers of the LPIs in the experimental group received the BCP once on the discharge day and then once a week for 1 month. Neonatal morbidity was defined as an outpatient department or emergency room visit due to an LPI's health problem. Results: The breastfeeding rate in the experimental group was significantly higher than in the control group at the fourth week after discharge $\left(x^{2}=7.17, p=.028\right)$. Five and two LPIs in the control group and the experimental group, respectively, visited a hospital due to neonatal jaundice. Neonatal morbidity was not significantly different between the two groups $\left(x^{2}=1.95, p=.164\right)$. Conclusion: The BCP was useful for improving the breastfeeding rates of LPIs and may have potential to reduce neonatal morbidity.

Key words: Breastfeeding; Coaching; Infant formula; Morbidity; Premature infant

\section{Corresponding author Gun Ja Jang \\ https://orcid.org/0000-0002-1028-8066}

Department of Nursing, Daegu University,

33 Seongdang-ro, 50-gil, Nam-gu, Daegu 42400, Korea

TEL +82-53-650-8391 FAX +82-53-650-8389

E-MAIL kjjang14@daegu.ac.kr

Received Jun 4, 2020 Revised Jun 15, 2020
Accepted Jun 20, 2020 (a) This is an Open Access article distributed under the terms of the Creative Commons Attribution NonCommercial License (http://creativecommons.org/licenses/by-nc/4.0/) which permits unrestricted noncommercial use, distribution, and reproduction in any medium, provided the original work is properly cited.

\section{INTRODUCTION}

\section{Need for Study}

The number of births has steadily decreased in Korea, from 465,900 births in 2008 to 326,800 births in 2018. However, the proportion of preterm births has increased from $5.5 \%$ of births $(25,655$ cases $)$ in 2008 to $7.8 \%(25,202)$ in 2018 [1]. Preterm or premature infants born at less than 37 weeks of gestation are likely to be at a greater risk of morbidity and mortality than full-term infants [2].

Late preterm infants (LPIs), born between 34 weeks and 36 weeks of gestation [3], are more likely than term infants to have respiratory distress, feeding difficulties, hyperbilirubinemia, hypothermia, hypoglycemia, and a septic workup just after birth $[4,5]$. In particular, LPIs cared for in a neonatal intensive care unit (NICU) were more likely to have those problems than LPIs initially cared for in a nursery [4]. Neonatal jaundice, dehydration, and poor weight gain are major health problems among breastfed LPIs after discharge [6]. In addition, LPIs who are breastfed are more likely to be readmitted due to neonatal jaundice or infections than term infants who are breastfed [5]. Hospital readmission related to neonatal jaundice and poor feeding is almost twice as common among 
breastfed LPIs as among non-breastfed LPIs, and LPIs are at a greater risk for breastfeeding-associated morbidity and poor breastfeeding establishment [7]. Therefore, improving breastfeeding support and education is likely to reduce neonatal jaundice and breastfeeding-associated hospital readmission [8].

Breastmilk jaundice occurs when bilirubin levels are 12 $\mathrm{mg} / \mathrm{dL}$ or higher [9]. The condition is caused by enterohepatic circulation issues, not by any specific ingredient in human milk. In other words, decreased breastmilk intake slows bowel movements and causes slower bilirubin elimination, aggravating jaundice. This is often referred to as breastfeeding failure jaundice [10]. However, in clinical settings, many neonatologists may encourage mothers to withhold breastfeeding and substitute breastmilk with infant formula when breastfeeding jaundice occurs in LPIs at a certain period postpartum. In addition, almost half of LPIs were discharged with advice to be fed with infant formula [11].

The American Academy of Pediatrics [12] recommends exclusive breastfeeding for the first 6 months, as breastmilk has been proven to be the most ideal nutritional source for the growth and development of newborns. However, as the breastfeeding rate of $63.8 \%$ at 1 month postpartum in LPIs is lower than the rate of $76.5 \%$ in term infants [13], LPIs are considered to be a population at an elevated risk for shortened breastfeeding duration, underscoring the need to develop specific breastfeeding support and education [13]. In particular, the breastfeeding rate at 1 month post-discharge in Korean LPIs (42.5\%) is lower than that of any other country [14]. As an association between lower breastfeeding rates and late preterm birth has been reported, high hospital support for breastfeeding is thought to be likely to increase the prevalence of exclusive breastfeeding. However, just $16.4 \%$ of LPIs received such support, compared with $30.7 \%$ of term infants [15].

The late preterm breastfeeding promotion interventions conducted in previous studies involved skin-to-skin contact to simulate breast milk production just after birth, cup feeding and triple feeding instead of bottle-feeding to improve breastfeeding, and a family care program recommending rooming-in in the NICU to facilitate breastfeeding by providing the mother with unrestricted access to the baby [2]. These interventions were primarily implemented in hospitals during the LPIs' hospital stay and discontinued after discharge.

In contrast, the breastfeeding coaching program (BCP) in this study was a repetitive, community-based intervention to establish exclusive breastfeeding for LPIs for 1 month after discharge to compensate for the known limitations of previous interventions. This program consisted of web-based breastfeeding education with practical lactation support, focusing on relatively unhealthy LPIs discharged from the NICU.
The main goal of the $\mathrm{BCP}$ was to successfully transit from mixed feeding (combination of breastfeeding and formula feeding) at discharge to exclusive breastfeeding at 1 month after discharge. A further motivation for the $\mathrm{BCP}$ was that mothers of LPIs admitted to the NICU have little experience of feeding their infants at the breast and have expressed a lack of breastfeeding education and support [15]. Moreover, the hospital readmission rates for LPIs can be reduced by $50 \%$ through breastfeeding education [16].

Thus, the effects of a BCP for LPIs discharged from the NICU on breastfeeding rate, LPIs' growth, neonatal jaundice, and neonatal morbidity during 1 month after discharge were investigated. This study aimed to determine the influence of the $\mathrm{BCP}$ on the breastfeeding rate and neonatal morbidity in LPIs.

\section{METHODS}

\section{Study Design and Participants}

This was a non-randomized quasi-experimental study with a time series design that investigated the effects of a BCP for mothers of LPIs on breastfeeding rates, LPIs' growth, neonatal jaundice, and neonatal morbidity. An article on the impact of the BCP on LPIs' growth and neonatal jaundice is being processed for publication in a different journal, and this is a separate study of the influence of this program on breastfeeding rates and neonatal morbidity for 1 month after LPIs' hospital discharge.

The required sample size was calculated as 36 using PASS 2008 (NCSS LLC, Kaysville, UT, USA), with a significance level of .05 , a statistical power of .08 , four repeated measurements and two groups (experimental and control) with breastfeeding rates of $55 \%$ and $25 \%$, respectively [17]. Forty LPIs were selected as the final sample, considering a possible withdrawal rate of $10 \%$.

The participants were 40 LPIs and their mothers in a NICU at a university hospital located in Daegu, South Korea. The mothers indicated that they understood the purpose of the study and consented to participate. The inclusion criteria were: a) mothers who did not have previous breastfeeding experience and intended to breastfeed; $b$ ) mothers who consented to weekly home visits during the study period; c) LPIs with a 1-minute Apgar score $\geq 5$ and/or a 5-minute APGAR score $\geq 7$; and d) LPIs who did not have any hemorrhagic problems. The exclusion criteria were: a) LPIs in whom oral feeding was delayed for more than 2 day due to respiratory problems or surgery; and b) LPIs in the NICU who were readmitted with medical issues after being discharged.

The participants were first allocated to the control group, 


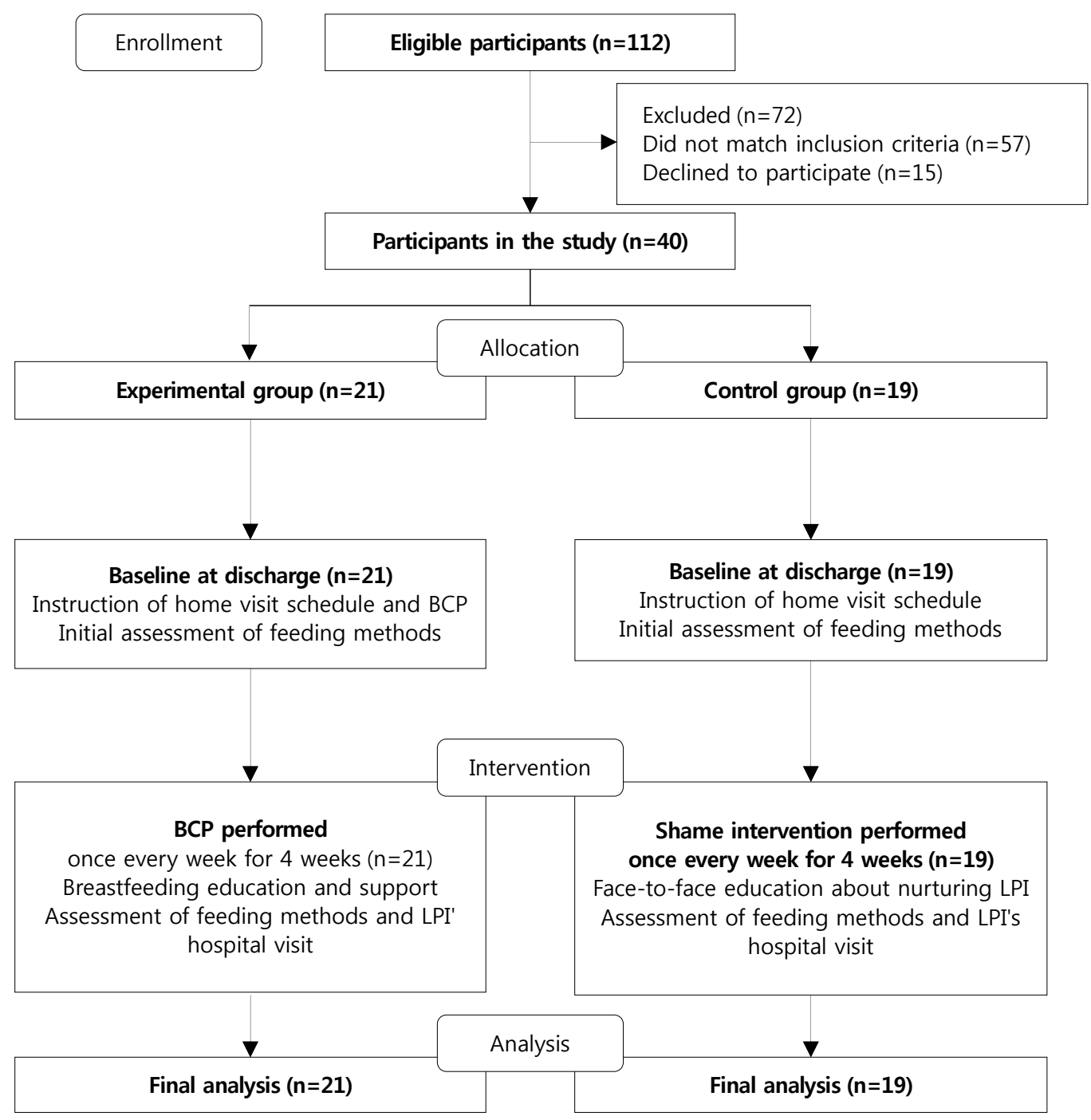

$\mathrm{BCP}=$ Breastfeeding coaching program; $\mathrm{LPI}=$ Late preterm infant.

Figure 1. Research flow diagram.

and then consecutively allocated to the experimental group to prevent contamination between participants. The number of participants allocated to the experimental and the control groups was 21 and 19, respectively (Figure 1).

\section{Intervention Program}

The BCP used a modified version of the breastfeeding support program (BSP) developed by Jang and Hong [17] for LPIs discharged from the NICU (Table 1). This program consisted of web-based breastfeeding education and practical breastfeeding support, and was provided for mothers in the experimental group on a weekly basis through a researcher's home visit. This website was available only when a researcher permitted mothers to access it.

On the day of discharge, mothers in the experimental group were given the home visit schedule and the webpage where the lactation education was available. On the first and second week after discharge, the researcher provided breastfeeding education through the web after assessing the infants' suckswallow-breathe coordination and oral-motor skills during the LPIs' feeding. Most of the LPIs were still not ready to directly feed from their mothers' breasts due to their physical and neuromuscular immaturity; therefore, the sessions were focused on regular pumping to stimulate breastmilk production. However, some mothers whose LPIs had sufficient oral-motor skills to feed were encouraged to latch at least once or twice a day. On weeks 3 and 4 , the researcher assessed the mother-infant dyad's feeding skills and helped the infants latch properly by correcting their positioning. Mothers were also taught ways of checking whether their babies were receiving enough milk given the difficulty in knowing exactly 
Table 1. Breastfeeding Coaching Program for Late Preterm Infants Discharged from the Neonatal Intensive Care Unit

\begin{tabular}{|c|c|c|c|c|}
\hline Session & Time & Contents & Method & Recommendation \\
\hline First & At discharge & $\begin{array}{l}\cdot \text { Feeding and physical characteristics of } \\
\text { LPIs } \\
\cdot \text { Education of proper feeding methods for } \\
\text { LPIs } \\
\cdot \text { Education on how to pump regularly }\end{array}$ & - Lecture via the web & $\begin{array}{l}\text { - Regular pumping to } \\
\text { stimulate breastmilk } \\
\text { production }\end{array}$ \\
\hline Second & $\begin{array}{l}\text { First home } \\
\text { visit }\end{array}$ & $\begin{array}{l}\text { - Assessment of LPI's feeding ability and } \\
\text { total amount of daily intake } \\
\text { - Evaluating whether the LPI's intake was } \\
\text { sufficient (weight gain or the number of } \\
\text { wet diapers) } \\
\text { - Providing an explanation about the LPI's } \\
\text { health condition and status of growth }\end{array}$ & - Lecture via the web & $\begin{array}{l}\text { Continuation } \\
\text { pumping until } \\
\text { breastfeeding is well } \\
\text { established }\end{array}$ \\
\hline Third & $\begin{array}{l}\text { Second home } \\
\text { visit }\end{array}$ & $\begin{array}{l}\text { - All of above } \\
\text { - Providing practical support for feeding } \\
\text { at the breast directly } \\
\text { - Encouragement of direct feeding at the } \\
\text { breast at least once a day }\end{array}$ & $\begin{array}{l}\text { One-on-one demonstration and } \\
\text { practice } \\
\text { · Practical support on latching } \\
\text { and breastfeeding }\end{array}$ & $\begin{array}{l}\text { Attempting to latch at } \\
\text { breast on a regular } \\
\text { daily basis }\end{array}$ \\
\hline Fourth & $\begin{array}{l}\text { Third home } \\
\text { visit }\end{array}$ & $\begin{array}{l}\cdot \text { All of above } \\
\cdot \text { Encouragement of direct feeding at the } \\
\text { breast as often as mother can }\end{array}$ & $\begin{array}{l}\text { One-on-one demonstration and } \\
\text { practice } \\
\text { Practical support on } \\
\text { breastfeeding skills }\end{array}$ & $\begin{array}{l}\text { - Facilitation latch at } \\
\text { breast and milk } \\
\text { transfer }\end{array}$ \\
\hline Fifth & $\begin{array}{l}\text { Fourth home } \\
\text { visit }\end{array}$ & $\begin{array}{l}\text { - All of above } \\
\text {. Continuation of exclusive breastfeeding } \\
8 \sim 12 \text { times a day for the first } 6 \text { months of } \\
\text { infancy }\end{array}$ & $\begin{array}{l}\text { - One-on-one demonstration and } \\
\text { practice } \\
\cdot \text { Practical support and } \\
\text { encouragement }\end{array}$ & $\begin{array}{l}\text { - Feeding at the breast } \\
\text { exclusively }\end{array}$ \\
\hline
\end{tabular}

LPI=Late preterm infant.

how much the infant consumed through direct nursing.

The control group was informed of the weekly home visit schedule upon discharge. At the following weekly visits, nurturing guidance for LPIs was provided by the same researcher. Questions on caring for LPIs, including the use of nutritional supplements such as iron, the outpatient visit schedule, and behavioral phenomena such as startle reflex, as well as breastfeeding-related questions, were answered with appropriate responses, but no practical support was provided to encourage breastfeeding. The average visit was between 1 hour and 1.5 hours in both group.

The BCP for the experimental group and nurturing guidance for the control group were provided through weekly home visit by the same researcher, who has an International Board Certified Lactation Consultant credential.

\section{Feeding Methods and Neonatal Morbidity}

Feeding methods were defined as follows: breastfeeding, mixed feeding, and formula feeding. Breastfeeding was defined as direct feeding at the breast or bottle-feeding with pumped breast milk. Mixed feeding referred to a combination of breastfeeding and supplementation with infant formula. Formula feeding was defined as being exclusively formulafed.

Based on a study conducted by Tomashek et al. [5], neonatal morbidity was defined as any health condition or illness that required hospital readmission or an observational hospital stay in the first month of life. An observational hospital stay was a hospital outpatient visit or an emergency room visit lasting less than 24 hours. When health issues in LPIs were reported, transcutaneous bilirubin levels and body weight were checked to evaluate the infants' condition.

\section{Data Collection}

Data were collected at a university hospital in Daegu, South Korea, which operates a nationally designated NICU center with 35 beds, between June 2017 and May 2018. Participants in the control group were collected from June to October 2017 and those in the experimental group, from November 2017 to May 2018. A nurse working as a lactation specialist in that 
hospital gathered the demographic and clinical characteristics of LPIs and feeding methods in the NICU from their electronic medical records on the day before discharge and contacted the researcher. The researcher checked the LPIs' feeding methods and whether they had experienced any health problems requiring a hospital outpatient visit or an emergency department visit once a week, from week 1 to week 4 after discharge.

\section{Statistical Analysis}

Data were analyzed using SAS version 9.4 (SAS Institute Inc., Cary, NC, USA). Descriptive statistics, the t-test, and the $x^{2}$ test were used to compare the clinical characteristics of the two groups of LPIs. Feeding methods each week and neonatal morbidity were compared between the two groups using the $x^{2}$ test. Feeding methods and neonatal morbidity were analyzed using logistic regression to adjust for clinical characteristics that were significantly different between the two groups.

\section{Ethical Considerations}

This study was approved by the institutional review board of Daegu University (1040621-201809-HR-026-02). A lactation specialist nurse explained the purpose of the study and the study procedures, and received informed consent. All participants were also told that they could withdraw from the study at any time without any disadvantages.

\section{RESULTS}

\section{Homogeneity Test of Clinical Characteristics between the Two Groups}

There were no significant differences in LPIs' clinical characteristics between the two groups, except the length of hospital stay and their diseases. The length of hospital stay was significantly longer in the experimental group (11.9 \pm 3.8 days) than in the control group ( $8.7 \pm 4.3$ days), and more LPIs in the experimental group had diseases than in the control group. Supportive feeding, including gavage feeding, in the experimental group was more frequent than in the control group, although this difference was not statistically significant. On the discharge day, none of LPIs had exclusive breastfeeding, and nearly two-thirds of LPIs were discharged with mixed feeding in both groups. The postmenstrual age, defined as gestational age plus weeks elapsed from birth, on the discharge day and the fourth week after discharge was around 36 weeks and 40 weeks in both groups, respectively (Table 2).

No significant differences were found between the two

Table 2. Homogeneity Test of Late Preterm Infants' Demographic and Clinical Characteristics between the Two Groups ( $N=40)$

\begin{tabular}{|c|c|c|c|c|c|}
\hline \multirow{2}{*}{ Variables } & \multirow{2}{*}{ Categories } & \multirow{2}{*}{$\begin{array}{c}\text { Cont. }(\mathrm{n}=19) \\
\mathrm{n}(\%) \text { or } \mathrm{M} \pm \mathrm{SD}\end{array}$} & \multirow{2}{*}{$\begin{array}{c}\text { Exp. }(n=21) \\
n(\%) \text { or } M \pm S D\end{array}$} & \multirow{2}{*}{$x^{2}$ or $\mathrm{t}$} & \multirow{2}{*}{$p$} \\
\hline & & & & & \\
\hline GA at birth (week) & & $34.9 \pm 0.7$ & $34.6 \pm 0.8$ & 1.43 & .160 \\
\hline Hospitalization day & & $8.7 \pm 4.3$ & $11.9 \pm 3.8$ & 2.48 & .018 \\
\hline Disease of newborn & $\begin{array}{l}\text { No } \\
\text { Yes }\end{array}$ & $\begin{array}{r}9(47.4) \\
10(52.6)\end{array}$ & $\begin{array}{r}3(14.3) \\
18(85.7)\end{array}$ & 5.20 & .023 \\
\hline $\begin{array}{l}\text { Type of disease } \\
\text { (multiple choice) }\end{array}$ & $\begin{array}{l}\text { Respiratory } \\
\text { Hyperbilirubinemia } \\
\text { Sepsis and infection }\end{array}$ & $\begin{array}{l}8(42.1) \\
5(26.3) \\
0(0.0)\end{array}$ & $\begin{array}{c}14(66.7) \\
14(38.1) \\
1(4.8)\end{array}$ & 0.60 & .742 \\
\hline Supportive feeding & $\begin{array}{l}\text { No } \\
\text { Yes }\end{array}$ & $\begin{array}{r}10(52.6) \\
9(47.4)\end{array}$ & $\begin{array}{r}5(23.8) \\
16(76.2)\end{array}$ & 3.54 & .060 \\
\hline Feeding type in NICU & $\begin{array}{l}\text { Breastfeeding } \\
\text { Mixed feeding } \\
\text { Formula feeding }\end{array}$ & $\begin{array}{c}0(0.0) \\
12(63.2) \\
7(36.8)\end{array}$ & $\begin{array}{c}0(0.0) \\
15(71.4) \\
6(28.6)\end{array}$ & 0.31 & .577 \\
\hline Feeding duration in NICU (day) & & $8.7 \pm 4.5$ & $10.7 \pm 4.6$ & 1.37 & .179 \\
\hline PMA (week) & $\begin{array}{l}\text { At discharge } \\
\text { First week } \\
\text { Second week } \\
\text { Third week } \\
\text { Fourth week }\end{array}$ & $\begin{array}{l}36.3 \pm 1.2 \\
37.2 \pm 1.5 \\
38.3 \pm 1.1 \\
39.4 \pm 1.1 \\
40.3 \pm 1.1\end{array}$ & $\begin{array}{l}36.0 \pm 1.2 \\
37.1 \pm 1.2 \\
38.2 \pm 1.2 \\
39.2 \pm 1.2 \\
40.2 \pm 1.2\end{array}$ & $\begin{array}{l}0.87 \\
0.28 \\
0.53 \\
0.48 \\
0.47\end{array}$ & $\begin{array}{l}.391 \\
.779 \\
.599 \\
.632 \\
.642\end{array}$ \\
\hline
\end{tabular}

Cont.=Control group; Exp.=Experimental group; GA=Gestational age; NICU=Neonatal intensive care unit; PMA=Postmenstrual age (gestational age at birth plus chronological age). 
groups in LPIs' birth weight, type of delivery, maternal age, and maternal diseases. The birth weight of the LPIs in the experimental group and control group were 2,156 $\pm 280 \mathrm{~g}$ and $2,296 \pm 389 \mathrm{~g}$, respectively. Most of the LPIs in the experimental group (81.0\%) and control group (84.2\%) were delivered by cesarean section. Most of the LPIs' mothers did not have any maternal diseases $(76.2 \%$ in the experimental group and $89.5 \%$ in the control group).

\section{Comparison of Feeding Methods after Hospital Dis- charge between the Two Groups}

There were no significant differences in the breastfeeding rate between the two groups at discharge, at the first week, at the second week, and at the third week. However, at the fourth week, the breastfeeding rate in the experimental group was significantly higher than that of the control group $\left(x^{2}=7.17\right.$, $p=.028)$. The breastfeeding rate in the control group remained the same $(10.5 \%)$ until the fourth week, while the experimental group showed a significant increase from $14.3 \%$ at discharge to $42.9 \%$ at the fourth week. After adjusting for the length of hospital stay and diseases of the newborns, the probability of breastfeeding was significantly higher in the experimental group than in the control group at the third week (odds ratio $[\mathrm{OR}]=13.70,95 \%$ confidence interval $[\mathrm{CI}]=1.20 \sim 156.99)$ and the fourth week (OR=20.64, 95\% CI=1.99 214.36) (Table 3).

\section{Comparison of Neonatal Morbidity and Description of Hospital Visits between the Two Groups}

The neonatal morbidity rate was $17.5 \%$, and two LPIs in the experimental group (9.5\%) and five LPIs in the control group $(26.3 \%)$ visited an outpatient department or an emergency room for treatment, but there was no significant betweengroup difference $\left(x^{2}=1.95, p=.164\right)$. Even after adjusting for the length of hospital stay and diseases of the newborns, the probability of a hospital visit was not significantly different between the two groups ( $\mathrm{OR}=0.32,95 \% \mathrm{CI}=0.05 \sim 2.22)$ (Table 4).

The main reason that all seven LPIs visited hospitals was neonatal jaundice. Six LPIs visited within the first week after

Table 3. Comparison of Feeding Methods after Discharge between the Two Groups

\begin{tabular}{|c|c|c|c|c|c|c|c|}
\hline \multirow{2}{*}{ Time } & \multirow{2}{*}{ Feeding method } & Cont. (n=19) & Exp. $(n=21)$ & \multirow{2}{*}{$x^{2}$} & \multirow{2}{*}{$p$} & Crude & Adjusted* \\
\hline & & n (\%) & n (\%) & & & OR $(95 \% \mathrm{CI})$ & OR (95\% CI) \\
\hline \multirow[t]{3}{*}{ At discharge } & Formula feeding & $7(36.9)$ & 7 (33.3) & \multirow[t]{3}{*}{1.08} & \multirow[t]{3}{*}{.584} & 1 & 1 \\
\hline & Mixed feeding & $10(52.6)$ & $11(52.4)$ & & & $1.10(0.28 \sim 4.26)$ & 0.81 (0.17 3.81) \\
\hline & Breastfeeding & $2(10.5)$ & $3(14.3)$ & & & $1.50(0.19 \sim 11.93)$ & $1.09(0.11 \sim 10.87)$ \\
\hline \multirow[t]{3}{*}{ At first week } & Formula feeding & 7 (36.9) & $6(28.6)$ & \multirow[t]{3}{*}{0.37} & \multirow[t]{3}{*}{.831} & 1 & 1 \\
\hline & Mixed feeding & $10(52.6)$ & $13(61.9)$ & & & $1.52(0.39 \sim 5.95)$ & $1.17(0.25 \sim 5.51)$ \\
\hline & Breastfeeding & $2(10.5)$ & $2(9.5)$ & & & $1.17(0.12 \sim 10.99)$ & $0.92(0.08 \sim 11.04)$ \\
\hline \multirow[t]{3}{*}{ At second week } & Formula feeding & $9(47.4)$ & $8(38.1)$ & \multirow[t]{3}{*}{5.40} & \multirow[t]{3}{*}{.067} & 1 & 1 \\
\hline & Mixed feeding & $7(36.8)$ & $10(47.6)$ & & & $1.61(0.71 \sim 6.24)$ & $0.68(0.13 \sim 3.47)$ \\
\hline & Breastfeeding & $3(15.8)$ & $3(14.3)$ & & & $1.13(0.18 \sim 7.24)$ & $2.28(0.24 \sim 22.13)$ \\
\hline \multirow[t]{3}{*}{ At third week } & Formula feeding & $13(68.4)$ & $8(38.1)$ & \multirow[t]{3}{*}{3.70} & \multirow[t]{3}{*}{.157} & 1 & 1 \\
\hline & Mixed feeding & $3(15.8)$ & $6(28.6)$ & & & 3.79 (0.76 19.05) & $2.24(0.36 \sim 13.89)$ \\
\hline & Breastfeeding & $3(15.8)$ & $7(33.3)$ & & & $3.25(0.63 \sim 16.79)$ & $13.70(1.20 \sim 156.99)^{\dagger}$ \\
\hline \multirow[t]{3}{*}{ At fourth week } & Formula feeding & $15(79.0)$ & $8(38.1)$ & \multirow[t]{3}{*}{7.17} & \multirow[t]{3}{*}{.028} & 1 & 1 \\
\hline & Mixed feeding & $2(10.5)$ & $4(19.0)$ & & & 3.75 (0.56 25.12) & $6.63(0.66 \sim 66.97)$ \\
\hline & Breastfeeding & $2(10.5)$ & $9(42.9)$ & & & $8.44(1.46 \sim 48.85)$ & $20.64(1.99 \sim 214.36)^{\dagger}$ \\
\hline
\end{tabular}

${ }^{*}$ Adjusted for length of hospital stay and disease of newborn; ${ }^{\dagger}$ There was a statistically significant difference $(p<.050)$; Cont. $=$ Control group;

$\mathrm{CI}=$ Confidence interval; Exp. $=$ Experimental group; $\mathrm{OR}=$ Odds ratio.

Table 4. Comparison of Neonatal Morbidity between the Two Groups

\begin{tabular}{|c|c|c|c|c|c|c|c|c|}
\hline \multirow{2}{*}{ Variable } & \multirow{2}{*}{ Category } & Total $(n=40)$ & Cont. (n=19) & Exp. $(n=21)$ & \multirow{2}{*}{$x^{2}$} & \multirow{2}{*}{$p$} & Crude & Adjusted* \\
\hline & & n (\%) & $\mathrm{n}(\%)$ & n (\%) & & & OR (95\% CI) & OR (95\% CI) \\
\hline \multirow{2}{*}{$\begin{array}{c}\text { Hospital } \\
\text { visit }^{\dagger}\end{array}$} & No & $33(82.5)$ & $14(73.7)$ & $19(90.5)$ & 1.95 & . 164 & 1 & 1 \\
\hline & Yes & 7 (17.5) & $5(26.3)$ & $2(9.5)$ & & & $0.30(0.05 \sim 1.75)$ & $0.32(0.05 \sim 2.22)$ \\
\hline
\end{tabular}

${ }^{*}$ Fisher's exact test; ${ }^{\dagger}$ Adjusted for length of hospital stay and diseases of the newborns; Cont.=Control group; CI=Confidence interval;

Exp.=Experimental group; $\mathrm{OR}=$ Odds ratio. 
Table 5. Description of Hospital Visits of LPIs in the Two Groups

$(N=40)$

\begin{tabular}{cllll}
\hline Case & Group & Main reason & Time of visit & Feeding method \\
\hline 1 & Control & Jaundice/eye discharge & First week & Formula \\
2 & Control & Jaundice & First week & Mixed \\
3 & Control & Jaundice & First week & Formula \\
4 & Control & Jaundice & First week & Formula \\
5 & Control & Jaundice & First week & Mixed \\
6 & Experimental & Jaundice & First week & Mixed \\
7 & Experimental & Jaundice/ GER & Third week & Breastfeeding \\
\hline
\end{tabular}

GER=Gastroesophageal regurgitation

discharge. One LPI visited a hospital around the third week after discharge. The feeding methods of the LPIs who visited hospitals were as follows: formula feeding in three infants, mixed feeding in three infants, and breastfeeding in one infant (Table 5).

\section{DISCUSSION}

This study investigated the influence of a BCP for LPIs who were admitted to the NICU on the breastfeeding rate and neonatal morbidity. LPIs' hospital stay in the experimental group was 3 days longer than in the control group. This fact reflects the fact that the LPIs in the experimental group had more neonatal diseases (e.g., hyperbilirubinemia, respiratory problems, and sepsis) and supportive feeding (e.g., gavage feeding) than those in the control group. This result is in line with the study of Medoff Cooper et al. [4], which reported that half of LPIs experienced neonatal health risks. However, the 8- to 11-day hospital stay in this study was longer than the 5-day length of hospitalization reported by DeMauro et al. [18].

The breastfeeding rate at the fourth week after discharge was significantly higher in the experimental group than in the control group. The breastfeeding rate in the control group remained the same (10.5\%) from the day of discharge to 4 weeks after discharge. In contrast, the breastfeeding rate in the experimental group increased from $14.3 \%$ on the day of discharge to $42.9 \%$ at the fourth week. After adjusting for the length of hospital stay and diseases of the newborns, in the experimental group, the probabilities of breastfeeding at the third and fourth weeks were 13.70 and 20.64 times higher, respectively, than in the control group. This result is attributed to a $\mathrm{BCP}$ that combined web-based breastfeeding education with one-on-one practical lactation support according to LPIs' physical maturity and capability of feeding. In other words, as the postmenstrual age of the LPIs approached 40 weeks by fourth week after discharge, the LPIs became mature enough to be breastfed exclusively; therefore, hospital-based breastfeeding support and education for LPIs extended for 1 month after discharge.

The breastfeeding rate in the experimental group was higher than that reported in the study of Lee and Jang [14], in which 106 Korean LPIs were analyzed and a breastfeeding rate of $42.5 \%$ was reported at the fourth week, but lower than that reported in the UK 2010 Infant Feeding Survey [19], according to which $75.4 \%$ of LPIs were breastfed at 6 weeks. This discrepancy indicates that Korean LPIs are less likely to be continued to be breastfed than LPIs in other nations. This result is consistent with a study on a breastfeeding support program provided for LPIs, which showed that the exclusive breastfeeding rate in the experimental group $(55 \%$; $=20)$ was higher than that in the control group $(25 \% ; n=20)$ at the fourth week [17]. In the study by Jang and Hong [17], the higher exclusive breastfeeding rate than was observed in this study reflected the conditions of the LPIs. Specifically, $50 \%$ of the LPIs in both groups in the study by Jang and Hong [17] were recruited from a nursery and had relatively fewer health issues, whereas the LPIs in this study were recruited from the NICU alone. This result also aligns with that reported by the study of Jang and Ju [20], which provided the mothers of 53 LPIs with an infant care education program focused on promoting breastfeeding and demonstrated a significantly higher breastfeeding rate $(73.1 \%)$ in the experimental group $(n=26)$ at 1 month after discharge than in the control group $(40.7 \%$; $n=27)$. Moreover, an integrated review of 13 breastfeeding education interventions for LPIs suggested that most interventions had positive effects on establishing exclusive breastfeeding [2]. The results of the studies by Goyal et al. [15] and Rayfield et al. [19] indicated that appropriate help and support at hospitals boosted exclusive breastfeeding by 2.21 and 3.14 times, respectively.

The neonatal morbidity rate of the LPIs in this study was $17.5 \%$. The neonatal morbidity in the experimental group and 
the control group was $26.3 \%$ and $9.5 \%$, respectively, and there was no significant difference between the two groups after adjusting for the length of hospital stay and diseases of the newborns. All the LPIs with neonatal morbidity visited an outpatient department or an emergency room due to neonatal jaundice. This is consistent with the finding of Escobar et al. [21] that the most common reason for rehospitalization of LPIs was neonatal jaundice, and the finding of Kim [22] that the major reasons for LPIs' readmission were jaundice and diarrhea. There were more hospital visits in this study than reported by Tomashek et al. [5], according to whom $4.3 \%$ of LPIs were likely to be readmitted or had an observational stay of less than 24 hours in hospitals. In addition, Jang and Ju [20] stated that none of the LPIs in the group provided an infant care education program for LPIs were readmitted, whereas one of the LPIs (3.7\%) in the control group was readmitted due to enteritis. Of particular note, the feeding methods of the seven LPIs who visited hospitals were formula feeding for three infants, mixed feeding for three infants, and breastfeeding for one infant. This result is different from that of many previous studies, which reported that breastfed LPIs were more likely to have neonatal jaundice than non-breastfed LPIs [5-7].

The BCP, as a community-based program, was more effective than a hospital-based breastfeeding support program [20], perhaps because the program was not merely a one-time intervention, but was repeatedly provided in the community. Breastfeeding promotion interventions are more effective when the prenatal and postnatal education at hospitals expands to the community setting [23]. In other words, the BCP successfully reinforced the breastfeeding education provided by the hospital by expanding it into the community.

Most breastfeeding promotion programs provide education and practical support in the hospital setting, but are discontinued after discharge. In contrast, this study continued the education program for 4 weeks after discharge.

The following limitations of this study are acknowledged: Firstly, the clinical characteristics of the experimental and control groups, including length of hospital stay and diseases of the newborns, were not homogeneous. Further research that ensures homogeneity in LPIs' clinical characteristics should be performed. Secondly, the same researcher provided the $\mathrm{BCP}$ education and investigated between-group differences, so the potential influence of the researcher being aware of the distribution of the groups on the results cannot be completely ruled out. However, the influence of the researcher was minimized, as the breastfeeding rate was observed directly. Thirdly, even though the mothers' intention to breastfeed was included as a selection criteria, mothers' psychological variables, including breastfeeding self-efficacy and confidence, and demographic characteristics were not considered as breastfeeding-related factors. Lastly, the results have limited generalizability due to the small sample size, and the study should be repeated with a larger number of participants and a longer study period. Nonetheless, the findings of this study are meaningful in that they imply that breastfeeding education could be expanded to community settings.

The positive effects of the $\mathrm{BCP}$ on the breastfeeding rate and neonatal morbidity among LPIs imply that breastfeeding support programs for LPIs should be continued for a certain period of time after discharge from the hospital and that tailored education should be provided based on the health status of the mother and the infant.

\section{CONCLUSION}

This study was conducted to evaluate the effects of a BCP on the breastfeeding rate and neonatal morbidity in LPIs, and found a positive effect on the breastfeeding rate and an indistinct effect on neonatal morbidity. Above all, the breastfeeding rate improved by 4 weeks after discharge in the experimental group, whereas it remained low in the control group. In addition, five LPIs in the control group and two LPIs in the experimental group visited hospitals during 4 weeks after discharge. This implies that practical breastfeeding education and support should be provided to mothers of LPIs on an ongoing basis to promote breastfeeding. Therefore, a BCP for LPIs should be utilized in hospitals and communities to a fuller extent.

\section{Conflict of interest}

No existing or potential conflict of interest relevant to this article was reported.

\section{REFERENCES}

1. Korean Statistical Information Service. 2018 live births by period of pregnancy [Internet]. Daejeon: Statistics Korea; 2019 [cited 2020 January 6]. Available from:

http://kostat.go.kr/portal/korea/kor_nw/1/1/index.board?b mode $=$ read\&aSeq $=377055$

2. Cartwright J, Atz T, Newman S, Mueller M, Demirci JR. Integrative review of interventions to promote breastfeeding in the late preterm infant. Journal of Obstetric, Gynecologic, and Neonatal Nursing. 2017;46(3):347-356.

https://doi.org/10.1016/j.jogn.2017.01.006

3. Engle WA. A recommendation for the definition of "late preterm" (near-term) and the birth weight-gestational age classification system. Seminars in Perinatology. 2006;30(1):2-7. 
https://doi.org/10.1053/j.semperi.2006.01.007

4. Medoff Cooper B, Holditch-Davis D, Verklan MT, Fraser-Askin D, Lamp J, Santa-Donato A, et al. Newborn clinical outcomes of the AWHONN late preterm infant research-based practice project. Journal of Obstetric, Gynecologic, and Neonatal Nursing. 2012;41 (6):774-785. https:// doi.org/10.1111/j.1552-6909.2012.01401.x

5. Tomashek KM, Shapiro-Mendoza CK, Weiss J, Kotelchuck M, Barfield W, Evans S, et al. Early discharge among late preterm and term newborns and risk of neonatal morbidity. Seminars in Perinatology. 2006;30(2):61-68.

https://doi.org/10.1053/j.semperi.2006.02.003

6. Chen $\mathrm{CF}$, Hsu MC, Shen $\mathrm{CH}$, Wang CL, Chang SC, Wu KG, et al. Influence of breast-feeding on weight loss, jaundice, and waste elimination in neonates. Pediatrics and Neonatology. 2011;52(2): 85-92. https://doi.org/10.1016/j.pedneo.2011.02.010

7. Radtke JV. The paradox of breastfeeding-associated morbidity among late preterm infants. Journal of Obstetric, Gynecologic, and Neonatal Nursing. 2011;40(1):9-24. https://doi.org/10.1111/j.1552-6909.2010.01211.x

8. Seagraves K, Brulte A, McNeely K, Pritham U. Supporting breastfeeding to reduce newborn readmissions for hyperbilirubinemia. Nursing for Women's Health. 2014;17(6):498-507. https://doi.org/10.1111/1751-486X.12078

9. Soldi A, Tonetto P, Varalda A, Bertino E. Neonatal jaundice and human milk. The Journal of Maternal-Fetal and Neonatal Medicine. 2011;24(sup 1):85-87. https://doi.org/10.3109/14767058.2011.607612

10. Academy of Breastfeeding Medicine Protocol Committee. ABM clinical protocol \#22: Guidelines for management of jaundice in the breastfeeding infant equal to or greater than 35 weeks' gestation. Breastfeeding Medicine. 2010;5(2):87-93. https://doi.org/10.1089/bfm.2010.9994

11. Adamkin DH. Feeding problems in the late preterm infant. Clinics in Perinatology. 2006;33(4):831-837. https://doi.org/10.1016/j.clp.2006.09.003

12. Section on Breastfeeding. Breastfeeding and the use of human milk. Pediatrics. 2012;129(3):e827-e841.

https://doi.org/10.1542/peds.2011-3552

13. Hackman NM, Alligood-Percoco N, Martin A, Zhu J, Kjerulff KH. Reduced breastfeeding rates in firstborn late preterm and early term infants. Breastfeeding Medicine. 2016;11(3):119-125. https://doi.org/10.1089/bfm.2015.0122
14. Lee SY, Jang GJ. Prevalence and predictors of exclusive breastfeeding in late preterm infants at 12 weeks. Child Health Nursing Research. 2016;22(2):79-96.

https://doi.org/10.4094/chnr.2016.22.2.79

15. Goyal NK, Attanasio LB, Kozhimannil KB. Hospital care and early breastfeeding outcomes among late preterm, early-term, and term infants. Birth. 2014;41(4):330-338.

https://doi.org/10.1111/birt.12135

16. Waldrop JB, Anderson CK, Brandon DH. Guideline-based educational intervention to decrease the risk for readmission of newborns with severe hyperbilirubinemia. Journal of Pediatric Health Care. 2013;27(1):41-50. https://doi.org/10.1016/j.pedhc.2011.09.002

17. Jang GJ, Hong YR. Effects of a breastfeeding support program on the prevalence of exclusive breastfeeding and growth in late preterm infants. Child Health Nursing Research. 2020;26(1):90-97. https://doi.org/10.4094/chnr.2020.26.1.90

18. DeMauro SB, Patel PR, Medoff-Cooper B, Posencheg M, Abbasi S. Postdischarge feeding patterns in early-and late-preterm infants. Clinical Pediatrics. 2011;50(10):957-962 https://doi.org/10.1177/0009922811409028

19. Rayfield S, Oakley L, Quigley MA. Association between breastfeeding support and breastfeeding rates in the UK: A comparison of late preterm and term infants. BMJ Open. 2015;5(11):e009144. https://doi.org/10.1136/bmjopen-2015-009144

20. Jang EH, Ju HO. Effects of an infant care education program for mothers of late-preterm-infants on parenting confidence, breastfeeding rates, and infants' growth and readmission rates. Child Health Nursing Research. 2020;26(1):11-22. https://doi.org/10.4094/chnr.2020.26.1.11

21. Escobar GJ, Greene JD, Hulac P, Kincannon E, Bischoff K, Gardner MN, et al. Rehospitalisation after birth hospitalisation: Patterns among infants of all gestations. Archives of Disease in Childhood. 2005;90(2):125-131. https://doi.org/10.1136/adc.2003.039974

22. Kim MJ. Readmission of late preterm infants after discharge from nursery. Korean Journal of Pediatrics. 2009;52(8):888-892. https://doi.org/10.3345/kjp.2009.52.8.888

23. Kim SK, Park S, Oh J, Kim J, Ahn S. Interventions promoting exclusive breastfeeding up to six months after birth: A systematic review and meta-analysis of randomized controlled trials. International Journal of Nursing Studies. 2018;80:94-105. https://doi.org/10.1016/j.ijnurstu.2018.01.004 